\title{
Uso, Variação e Norma na Tradição Gramatical Latina
}

\author{
Use, Variation and Norm in the Latin Grammatical Tradition
}

Fábio da Silva FORTES*

Resumo: Embora sejam temas de relevância para o pensamento linguístico moderno, o uso, a variação e a norma da linguagem foram também abordados por autores latinos no âmbito dos discursos retórico e gramatical. Considerando, sobretudo, a obra de Quintiliano (séc. I d.C.) e os tratados gramaticais de Donato e Diomedes (séc. IV d.C.), este artigo tem por meta oferecer uma apresentação de como estes conceitos se afiguravam no discurso metalinguístico antigo, atrelados à noção de Latinitas, que codificava a norma social e linguística para o uso linguístico, separando a linguagem do romano culto - adequada à produção de textos oratórios - da linguagem eivada de elementos bárbaros - inadequada em determinados contextos. A noção de Latinitas emergia, assim, de uma reflexão antiga que considerou as variações da língua segundo diferentes usos e estipulou certa norma que era contextualmente dependente.

Palavras-chave: Variação. Norma. Latinitas. Tradição gramatical latina.

Abstract: Despite being relevant themes for the modern linguistic thought, the language use, variation and norm have been also addressed by Latin authors under the scope of the rhetoric and grammatical discourses. By considering the work of Quintilian (c. I a.D.) and the grammatical treatises by Donat and Diomedes (c. IV a.D.), this article aims at offering a presentation of how such concepts figured in the ancient metalinguistic discourse, associated to the notion of Latinitas, which codified the social and linguistic norm for the language use, setting apart the schooled Roman language adequate to the production of oratory texts - from the language full of

* Doutorado em Linguística (Estudos Clássicos) pela Universidade Estadual de Campinas (2012). Professor Adjunto de Grego Clássico e Latim do Departamento de Letras da Universidade Federal de Juiz de Fora. Contato: fabiosfortes@yahoo.com.br. 
Barbarian elements - inadequate in certain contexts. The notion of Latinitas arose thus from an ancient reflection which considered the language variations according to different uses, and stipulated a certain norm contextually dependent.

Key-words: Variation. Norm. Latinitas. Latin grammatical tradition.

\section{Introdução}

Mas o fato de a língua se manter parcialmente idêntica a si mesma e o fato de incorporar novas

tradições é, precisamente, o seu caráter como língua e o seu caráter de "objeto histórico". Um objeto histórico só o é, se é, ao mesmo tempo,

permanência e sucessão. (Coseriu, 1979, p. 237-238)

As palavras em epígrafe, do linguista romeno Eugênio Coseriu, marcam o embate, na linguística contemporânea, de uma das maiores dicotomias teóricas dessa disciplina ao longo do século XX: a abordagem defendida pelo autor, que inclui a historicidade das línguas como uma particularidade relevante no desenvolvimento das teorias linguísticas, em oposição a outra abordagem, que advoga uma visão a-histórica para a compreensão dos fenômenos linguísticos. Essa dicotomia já era apresentada, é verdade, por Ferdinand de Saussure, quando, em seu Curso de Lingüística Geral (1916), explicitava a diferença entre sincronia e diacronia, elegendo, por conseguinte, a primeira enquanto manifestação do sistema linguístico (langue) e como objeto de estudos privilegiados para a Linguística.

A tendência de se tomar a língua dissociada de sua história prevaleceu no século XX, nas perspectivas teóricas do estruturalismo americano de orientação bloomfieldiana e, posteriormente, nos trabalhos gerativistas (MATTOS E SILVA, 2008, p. 11 seq.). A noção de língua como sistema abstrato e, posteriormente, competência, governada, nos dois casos, por regras lógicas, reinava soberana até meados do século XX. A partir de então, o tema da língua situada no tempo ou na história - e a expressão disso, que é a mudança linguística - começou a se insinuar no cenário dos estudos linguísticos. Um texto que assinala essa mudança é, sem dúvida, o seminal ensaio de Weireich, Labov e Herzog (Princípios empiricos para uma teoria da 
mudança linguística, obra de 1968, traduzida para o português em 2006). Assim, foi sobretudo a partir desse texto que linguistas como Labov, Coseriu e outros paulatinamente abriram espaço para os estudos de uma 'linguística histórica', cuja compreensão de língua enquanto fenômeno histórico e social nela inseriu a realidade empírica da variação e mudança linguísticas. Essa realidade descreve, nas palavras de Coseriu, citadas no epitáfio, um quadro de "permanência e continuidade" que definem o próprio estatuto de língua enquanto objeto histórico.

Neste artigo, queremos demonstrar que reflexões em torno das línguas enquanto construções variáveis, históricas e, portanto, suscetíveis de serem normatizadas segundo determinados usos, já estavam presentes, no entanto, nos primórdios da tradição gramatical ocidental. Compulsando tratados de retórica e gramática produzidos na Antiguidade greco-romana, demonstramos, no primeiro item, como a consciência do caráter histórico da linguagem levou os autores latinos a elaborar o conceito de Latinitas no âmbito da retórica romana e, no segundo item, como esse conceito foi apropriado pelo discurso gramatical para produzir uma "norma" para determinados usos da linguagem. Adotamos os procedimentos metodológicos próprios dos Estudos Clássicos, que conferem privilégio à leitura e análise dos textos originais gregos e latinos contemplados nesta análise - Quintiliano, séc. I d.C.; Donato, séc. IV d.C; e Diomedes, séc. IV d.C. -, considerando, também, os apontamentos modernos acerca dos estudos gramaticais antigos (LAW, 1987; BARATIN, 1993; CANTÓ, 1997, PEREIRA, 2006, DESBORDES, 2007).

\section{Uso, Variação e Norma: questões de retórica?}

Não precisaríamos evocar os linguistas para trazer à consciência o fato empírico de que as línguas variam não somente em função do tempo, mas também de outras variáveis histórico-culturais; variações que, no mais das vezes, obedecem não a causalidades de ordem estritamente lógico-estrutural, mas a pressões próprias do uso que delas fazem os seus falantes, consciente ou inconscientemente.

Um usuário atento da língua portuguesa falada no Brasil, por exemplo, observará que o modo de falar de uma pessoa criada no campo, que teve pouco acesso à escolarização formal e tem mais de sessenta anos é bem diferente da forma como um jovem universitário, criado no Rio de Janeiro ou em outro grande centro urbano, usa a sua língua. As falas do jovem e do 
idoso deixam transparecer o fato de que as línguas se modificam com as gerações, mas também revelam outras variáveis, como a variável geográfica (campo versus cidade) e social (indivíduo escolarizado versus não escolarizado). Em última análise, os falares diferentes determinarão formas socialmente prestigiadas da língua, chamadas "cultas" ou "padrão", e outras formas que sofrem estigmatização e, em certos casos, preconceito social e linguístico (BAGNO, 2001, p. 15) ${ }^{1}$.

Do mesmo modo que constatamos que a nossa própria língua não é um edifício monolítico e uniforme, mas apresenta variações com o tempo e com as diferentes comunidades de falantes, representando, em suma, diferentes usos, perguntaríamos se também os antigos não foram conscientes do fato de que suas línguas fossem realidades históricas, ainda que não se referissem a elas nesses termos. Se assim não o fosse, esse fato não teria chamado a atenção dos estudiosos que, na Antiguidade, se ocuparam da linguagem em seus diferentes domínios e disciplinas.

Já Horácio assim afirmava, em sua Epistula ad Pisones, texto que a tradição após Quintiliano (Inst. or., VIII, 3) consagrou como Arte poética, dado o caráter dos conteúdos que nela se apresentam:

Muitas palavras que já caíram vão renascer, e aquelas que agora gozam das honras cairão, se o uso assim o quiser, em cujas mãos está o arbítrio, o direito e a norma do falar ${ }^{2}$.

(Horácio ${ }^{3}$, Ep. ad Pis., 70 seq.)

1 “Ora, a verdade é que, no Brasil, embora a língua falada pela grande maioria da população seja o português, esse português apresenta um alto grau de diversidade e de variabilidade, não só por causa da grande extensão territorial do país - que gera as diferenças regionais, bastante conhecidas, e também vítimas de muito preconceito mas principalmente por causa da trágica injustiça social que faz do Brasil o segundo país com a pior distribuição de renda em todo o mundo." (BAGNO, 2001, p. 15).

2 Salvas as indicações em notas, os textos em língua estrangeira foram todos traduzidos por nós. Apresentamos os originais em rodapé para que o leitor competente possa cotejar com a tradução oferecida. Cf. Multa renascentur quae iam cecidere, cadentque quae nunc sunt in honore nocabula, si uolet usus, quem penes arbitrium est et ius et norma loquendi.

3 Para as referências das obras antigas, adotamos a convenção dos Estudos Clássicos, apondo o nome latino da obra abreviado após o autor, livro e/ou parágrafo das edições consultadas. As demais informações sobre a data da publicação das edições consultadas estão nas Referências. 
A concepção de língua que nestes versos se apresenta é a de uma realidade histórica: o tempo é capaz de operar mudanças na língua, fazendo perderem-se palavras desusadas, inserindo e reinserindo vocábulos novos. Assim, em Horácio, é o uso (usus) que representa o fator decisivo nessas mudanças: nele se definem o arbítrio (arbitrium), o direito (ius) e a norma (norma) do falar.

Porém, como entender melhor os conceitos de uso (usus) e norma (norma) no contexto antigo romano, no qual o poeta se inseria? De fato, aquilo que a Horácio, em sua epístola, aparecia somente en passant, sem maiores explicações, é por Quintiliano um território muito mais vastamente explorado. É ao autor da Institutio oratoria - obra, sem dúvida, basilar para a formação dos oradores na Roma imperial do século I d.C. - que se atribui um conceito de linguagem formado a partir da articulação de princípios lógicos/racionais (ratio), antiguidade (uetustas), autoridade (auctoritas) e uso (consuetudo) ${ }^{4}$, nos termos que lemos, por exemplo, na passagem: "Há ainda uma observação para quem fala e para quem escreve. A língua consta de um sistema lógico, antiguidade, autoridade e uso"5 (Quintiliano, Inst. or., I, 6, 1).

A língua (sermo), tanto para quem fala, discursa, produz e apresenta peças oratórias - o orador - quanto para quem a expressa por escrito é, para o mestre de retórica, uma realidade regulada por princípios a ela intrínsecos, organiza-se segundo certa lógica das coisas, definida pelo termo ratio, que, apesar de difícil tradução, tem identidade com certa nuance do lógos grego, e que podemos entender, como a “organização lógica”, intrínseca, da língua. Por outro lado, o valor igualmente reconhecido da tradição (a auctoritas, "autoridade" e uetustas, "antiguidade" das formas empregadas), também remetem para a noção de uso da linguagem (consuetudo/usus). Em outras palav ras, isso quer dizer que, em Quintiliano, o uso da linguagem não é sinônimo das formas vulgares ou populares da fala, mas se associa a uma modalidade corrente de fala empregada por pessoas escolarizadas, conhecedoras da tradição letrada. Isso é o que vemos em outra passagem

${ }^{4}$ Embora o termo consuetudo, em seus sentidos usuais, remeta a "costume", "hábito", traduzimo-lo aqui como "uso", acepção técnica aceitável para o texto de Quintiliano, ademais, escolha tradutória de Pereira (2006), que seguimos. Neste sentido, consuetudo é o "hábito/costume dos falantes", algo semelhante ao "uso linguístico".

${ }^{5}$ Cf. Est etiam sua loquentibus obseruatio, sua scribentibus. Sermo constat ratione uetustate auctoritate consuetudine. 
de sua Institutio oratoria (I, 6, 43-45), quando o mestre de retórica especifica o seu conceito de "uso linguístico", com vistas ao estabelecimento de determinada "norma" para a produção dos textos da oratória:

Resta, pois, o uso. Com efeito, seria quase ridículo preferir a linguagem com a qual os homens falaram àquela com a qual falam. E, seguramente, que outra coisa é uma linguagem antiga, senão uma velha forma de falar? Mas é necessário que se observe com critério e se defina em primeiro lugar aquilo que tratamos e chamamos de "uso". Se se tomar o nome tendo em vista o que fazem muitos, oferecer-se-á um preceito por demais perigoso não apenas para o discurso, mas também, o que é mais grave, para a vida. Ora, onde residirá a vantagem de tomar por bom aquilo que agrada à maioria? Portanto, da mesma forma que depilar-se, cortar os cabelos em camadas e beber em excesso nos banhos, por mais que tais coisas tenham invadido a cidade, não constituem uso, porque nenhuma delas está livre de censura - ao contrário, nós nos lavamos, cortamos os cabelos e fazemos juntos as refeições segundo um determinado costume -, assim, também, no falar não se tomará por regra de linguagem algo de vicioso que muitos adotaram. Com efeito, para não falar do modo como os incultos habitualmente se expressam, sabemos que, muitas vezes, os teatros inteiros e toda a multidão do circo se expressam rudemente. Logo, chamarei de "uso da linguagem" o consenso dos instruídos, do mesmo modo que o consenso dos bons se chama "modo de viver". ${ }^{6}$ (Quintiliano, Inst. or., I, 6, 43-45)

${ }^{6}$ Tradução de Pereira (2006, p. 159-160): Superest igitur consuetudo: nam fuerit paene ridiculum malle sermonem quo locuti sint homines quam quo loquantur. Et sane quid est aliud uetus sermo quam uetus loquendi consuetudo? Sed huic ipsi necessarium est iudicium, constituendumque in primis id ipsum quid sit quod consuetudinem nocemus. Quae si ex eo quod plures faciunt nomen accipiat, periculosissimum dabit praeceptum non orationi modo sed, quod maius est, uitae: unde enim tantum boni ut pluribus quae recta sunt placeant? Igitur ut uelli et comam in gradus frangere et in balneis perpotare, quamlibet haec inuaserint ciuitatem, non erit consuetudo, quia nibil horum caret reprensione (at lanamur et tondemur et conuinimus ex consuetudine), sic in loquendo non si quid uitiose multis insederit pro regula sermonis accipiendum erit. Nam ut transeam quem ad modum unlgo imperiti loquantur, tota saepe theatra et omnem circi turbam exclamasse barbare scimus. Ergo consuetudinem sermonis nocabo consensum eruditorum, sicut uiuendi consensum bonorum. 
Logo de partida, fica clara a oposição que se fez entre o modo como os homens se expressavam no passado e aquele como se expressavam na contemporaneidade do texto de Quintiliano, o que revela a consciência do mestre de retórica do fato de que as línguas eram realidades históricas e, portanto, eram suscetíveis a mudanças com o tempo. Segundo Quintiliano, aliás, um uso deliberado de uma forma linguística "antiga" em detrimento de um uso corrente tornaria a fala algo ridícula. No entanto, também fica explícito que o conceito de uso em Quintiliano não é sinônimo da fala corriqueira e vulgar compartilhada pela maioria, mas é produto de uma convenção entre pessoas instruídas (consensus eruditorum). Ao passo que o "consenso dos instruídos" definirá uma norma própria para a produção dos discursos dos oradores (cuja formação, não se esqueça, é o objetivo da obra), a fala comum, assim como os costumes vulgares, é eivada de vícios (uitia), que cumpria evitar.

As considerações de Quintiliano levam-nos a crer que, de fato, na Antiguidade romana, havia a consciência de que a língua engendrava um conjunto de variantes, algumas, evidentemente, de prestígio social e, portanto, mais adequadas à fala dos oradores, e outras que, à maneira dos costumes considerados "censuráveis", eram por Quintiliano imputadas como inadequadas para a constituição dos textos proferidos segundo o gênero oratório, sobre o qual disserta em sua obra. A relação que se estabelece também entre a "norma da língua" e a "norma social" é, de resto, um posicionamento ético e filosófico, dado o caráter formador e educativo da Institutio oratoria.

Deixando de lado, por enquanto, a relação ética que se estabeleceu entre o caráter do indivíduo e a sua linguagem, consideremos ainda mais cuidadosamente o significado da constituição dessa norma linguística no âmbito desse texto que não era propriamente gramatical, mas que tinha como meta a apresentação dos conceitos fundamentais da retórica antiga com vistas à formação de futuros oradores.

Ao estabelecer uma norma que tinha por base o "uso" como o "consenso dos instruídos" (consensus eruditorum), emergia na formulação de Quintiliano uma noção já havia bastante tempo conhecida pelos romanos: a Latinitas. Díaz y Díaz (1951, p. 33) afirma que o conceito de Latinitas era um decalque do grego Hellçnismós e não somente designava a "correção/ adequação à norma linguística", mas também se configurava como a propriedade essencial do mundo latino. Desbordes (2007, p. 91) acrescenta 
ainda que Latinitas envolvia, de fato, um modelo identitário romano pelo viés da língua e, por meio da diferença, definia as fronteiras entre a cultura latina e as demais, tendo-se por base as dicotomias entre: 1) o latim e as línguas "bárbaras"; 2) o "bom latim" e o "mau latim", segundo as finalidades visadas (um texto oratório, por exemplo, deveria ter linguagem diversa daquela de uma epístola pessoal); 3) o latim e o grego.

Conforme a estudiosa afirma (DESBORDES, 2007, p. 92), o conceito de Latinitas comparece na tradição textual pela primeira vez na Retórica a Herênio, obra de autor desconhecido, provavelmente escrita em algum momento da década de 80 a.C.. Apresentamos, a seguir, um excerto da obra em que o termo aparece, que tem, por isso mesmo, importância para compreendermos a constituição desse conceito no âmbito da retórica:

Porque se deve examinar a elocução nesses gêneros, foi dito e vejamos agora que sorte de coisas uma elocução apropriada e completa deve apresentar. Para ser inteiramente apropriada ao orador, a elocução deve conter três coisas: elegância, composição e dignidade. Elegância é o que faz com que certa passagem pareça ser dita de forma pura e clara. Ela se reparte em correção [Latinitas] e clareza. A Latinitas é o que mantém a língua pura, dela removendo todos os vícios. Os vícios na linguagem, porque a tornam menos latina, podem ser de dois tipos: solecismo e barbarismo. Há solecismo quando não se concatena bem a palavra seguinte às outras palavras. Há barbarismo quando, no interior das palavras, algo se produz viciosamente. Podemos evitar tais coisas por intermédio do sistema [ratio] que abordaremos de forma clara na arte gramatical. ${ }^{7}$

$$
\text { (Her., 4, 17) }
$$

7 Cf. Quoniam, quibus in generibus elocutio uersari debeat, dictum est, uideamus nunc, quas res debeat habere elocutio commoda et perfecta. Quae maxime admodum oratori adcommodata est, tres res in se debet habere: elegantiam, conpositionem, dignitatem. Elegantia est, quae facit, ut locus unus quisque pure et aperte dici uideatur. Haec tribuitur in Latinitatem, explanationem. Latinitas est, quae sermonem purum conseruat, ab omni uitio remotum. Vitia in sermone, quo minus is Latinus sit, duo possunt esse: soloecismus et barbarismus. Soloecismus est, cum in uerbis pluribus consequens uerbum superius non adcommodatur. Barbarismus est, cum uerbis aliquid uitiose efferatur. Haec qua ratione uitare possumus, in arte grammatica dilucide dicemus. 
Inicialmente, convém relembrar que a elocução (elocutio) é uma das partes que, ao lado da invenção (inuentio), disposição (dispositio), memória (memoria) e ação (actio) compunham o sistema da retórica antiga (LAUSBERG, 1973; BERRY, 2005, p. 259). Na Retórica a Herênio, ela se divide em três partes - "composição" (compositio), "dignidade" (dignitas) e "elegância" (elegantia) -, sendo que esta última se subdivide em "correção" (Latinitas) e "clareza" (explanatio). Ao que nos parece à primeira vista, a noção de Latinitas se alinha a uma perspectiva que considera certa "pureza" (puritas) da língua, que se atinge evitando os "vícios da linguagem", em especial o barbarismo (barbarismus) e o solecismo (soloecismus), que tornariam a língua menos latina.

No entanto, apesar de assim o parecer à primeira vista, não estamos diante de um relato de caráter simplesmente prescritivo acerca da língua. A exposição em Herênio - obra que, como sabemos, teria sido, provavelmente, produzida anos antes das obras de maturidade de Cícero, como o Brutus, e bem antes da Institutio oratoria, de Quintiliano, e, portanto, seria possível crer que estivesse na fundamentação teórica dos tratados de retórica escritos por ambos os autores - descortina uma reflexão metalinguística que, pelo viés do estabelecimento de uma norma apropriada ao discurso retórico, vai além da mera prescrição do que seria o modus scribendi/loquendi ideal para os oradores romanos (suscitando, é verdade, uma leitura que ultrapassa aquela que a reduz a uma simples normatização; leitura que, em última instância, permitiu que dos antigos retóricos se tomassem argumentos com vistas à defesa de posições conservadoras acerca da língua até mesmo no universo longínquo da contemporaneidade $\left.{ }^{8}\right)$.

É preciso reconhecer, porém, que a noção de Latinitas, longe se ser tomada de forma simplista como o critério que oporia, na Antiguidade, as noções absolutas do certo/errado, em se tratando de língua, é um conceito

${ }^{8}$ Pereira (2002, p. 128 seq.) expõe o artigo de conhecido gramático do século XX, Napoleão Mendes de Almeida, que, ao defender o seu conservadorismo diante da língua, com a instituição e defesa das categorias de certo/errado, cita e lê autores clássicos como Cícero e Quintiliano, que teriam, na Antiguidade, produzido um discurso favorável ao seu posicionamento que, de resto, estava na contramão das pesquisas linguísticas de seu século. O elemento clássico é, por assim dizer, utilizado para a defesa de uma ideologia linguística, embora de uma maneira que, em si, o deforma, visto que produz uma simplificação da noção de Latinitas. Esse é um exemplo de uma leitura enviesada do legado clássico, para legitimar posicionamentos modernos que eram ausentes das reflexões metalinguísticas da Antiguidade. 
que engendra consequências mais amplas. Em primeiro lugar, é possível destacar dessa passagem o conceito de Latinitas enquanto modelo identitário romano (DESBORDES, 2007, p. 91): não somente produz uma norma linguística, mas engendra um código identitário que, de modo geral, separava o cidadão romano daqueles que não falavam latim e não compartilhavam da cultura romana. A "pureza” linguística não diz respeito somente à variedade "mais correta", como, apressadamente, pensariam aqueles que consideram a linguagem pelo prisma da lógica do certo/errado (seja para defendê-la, seja para refutá-la). A "pureza" é a própria língua/cultura latina, definidora da ontologia do romano, é a sua essência. É, por conseguinte, o atributo indissociável desta língua que, como afirmaria Quintiliano, mais tarde, conferia apreço à "antiguidade" (uetustas) e à "autoridade" (auctoritas).

Em síntese, ser latino é usar a língua segundo esse critério e é em defesa desse ideal latino que se deveria evitar, por conseguinte, tudo o que atentasse contra a língua em sua forma original. Desse modo, os vícios de linguagem catalogados pelos rétores e gramáticos latinos não são, também, somente "erros de latim" (em uma analogia grotesca com aqueles que seriam "erros de português" para os normativistas do presente): os uitia são modos de expressão pela linguagem que identificam o seu falante como não sendo romano - ou sendo "menos latino" -, deixando transparecer uma identidade desprestigiosa, até mesmo bárbara. No próximo item veremos como essa noção, por um lado linguística e, por outro, étnica/social também está presente nas considerações dos gramáticos latinos.

\section{A Latinitas e a Questão da Correção Gramatical}

É interessante observar que, já na Rhetorica ad Herennium, a grammatica comparecia como esse domínio de estudos especializado em torno da Latinitas. As relações entre a escola do grammaticus e a do rhetor em Roma são bastante conhecidas. Como demonstram Marrou (1975) e Cantó (1997), no período clássico romano, a ars grammatica e a ars rhetorica se associavam em um grande programa de educação do romano fundamentado pela linguagem ${ }^{9}$, que se dividia entre a escola que propiciava a aquisição dos fundamentos elementares de leitura e escrita, além do uso do ábaco para

9 Cf. Law (1987, p. 11): "Roman education centred on the acquisition of linguistic skills" ("A educação romana centrava-se na aquisição de habilidades linguísticas”). 
operações matemáticas básicas (a escola do magister ludi); a escola que conferia aos adolescentes o contato com os textos do cânone poético, além do refinamento da Latinitas (a escola do grammaticus); e, finalmente, aquela última etapa à qual ascendiam os patrícios após a tomada da toga viril, na qual eram preparados para a leitura e produção de gêneros em prosa, sobretudo retóricos, com fins à carreira forense (a escola do rhetor).

Assim, no quadro maior da educação romana, a gramática se colocava, em sua origem, como uma matéria propedêutica ao estudo da retórica. Esse caráter preparatório vincula-se, de certa maneira, à asserção do autor da Retórica a Herênio, que, no trecho que examinamos anteriormente, delega a essa disciplina uma parte da elocutio: o cuidado com a Latinitas e, por conseguinte, com os "vícios de linguagem". Todavia, no domínio da gramática, a Latinitas tornara-se um de seus conceitos fundamentais, a bem dizer, o cerne daquela que a crítica contemporânea destaca como a "terceira parte” das gramáticas antigas (DESBORDES; BARATIN, 1981, p. 215), ocupada com as ocorrências louváveis e condenáveis na linguagem; entre essas últimas, em especial, o barbarismo e o solecismo, como desdobramentos do exame da Latinitas.

Embora possamos identificar formulações dos conceitos de barbarismo e solecismo também no âmbito da dialética estoica, será sobretudo no escopo das artes gramaticais latinas que eles adquirem certo caráter normativo - novamente, aqui não vinculamos a palavra norma aos sentidos usuais e correntes do termo, quando aplicados às nossas línguas em nosso tempo, mas a um conjunto de propriedades linguísticas que caracterizavam a latinidade dos textos da tradição poética romana, em particular; mas também da linguagem comum dos cidadãos romanos cultos.

Pois, conforme salienta Desbordes (2007, p. 97), importava para os compêndios gramaticais menos uma apreciação sobre o que se considerava 'correto' em termos abstratos de língua, que uma representação do que se intuía como adequado na linguagem escrita e literária, que traduzia o bom uso da língua também característico dos cidadãos romanos letrados. Vale dizer que o exame dessa questão se associava, originalmente, àquela concepção de gramática como estudo dos textos, que está presente desde as reflexões de Dionísio Trácio (FORTES, 2012, p. 120).

Conforme avalia Baratin (1993, p. 209), um enunciado como urbem quam statuo uestra est ("a cidade que estou fundando é vossa", Aen., I, 577) possibilitava aos gramáticos observar que o emprego de acusativo urbem, quando, de fato, ter-se-ia esperado um nominativo, sujeito do verbo sum, 
denotando uma variação análoga ao solecismo, mas que, pelo fato de se encontrar em um texto canônico, era aceitável por sua tradição. Em outras palavras, o estudo dos textos permitia aos gramáticos reconhecer os desvios não como meros erros, mas como variações dentro do mesmo sistema, algumas das quais negativas - como características de uma fala estrangeira e bárbara: o barbarismo, o solecismo, etc. - e outras positivas, empregadas pelos poetas como artifícios literários, abonadas pela tradição - as "virtudes da linguagem": metaplasmo, figura, tropo, etc.. Em outras palavras: "os gramáticos ultrapassam os limites estritos da correção para entrar em um domínio mais largo: aquele das variações em geral"10 (BARATIN, 1993, p. 210).

Assim, a Latinitas representava, com efeito, uma noção complexa, que considerava, ao menos, dois aspectos: 1) um conjunto de critérios de referência cultural e linguística para o romano culto: o latim em oposição às línguas estrangeiras; 2) um estudo das variedades de linguagem presentes nos textos da tradição poética, definidores dos uitia e virtutes: o latim literário em oposição ao latim vulgar, falado. Esses dois aspectos, associados, permitiram aos gramáticos não somente reconhecer a sua língua como diferente dos falares bárbaros, como também encontrar no interior de sua própria tradição literária elementos que, posteriormente, lhes permitiriam uma análise da variação linguística, como ficaria mais claro, no século VI, com a obra de Prisciano, conforme examinamos em nossa tese (FORTES, 2012).

Em outras palavras:

A partir do momento que o latim assume o barbarismo, ele deixa de ser bárbaro. Não há barbarismos nas línguas bárbaras, que são uniformemente representativas da alteridade. Em contrapartida, podese distinguir um latim puro de suas formas corrompidas, onde a alteridade se insinua, mas das quais se pode e se deve extirpá-lo. ${ }^{11}$

(Desbordes, 2007, p. 96).

${ }^{10}$ Cf. "Les grammariens dépassaient le cadre strict de la correction pour entrer dans un cadre plus large: celui, à nouveau, de l'écart en general".

${ }^{11}$ Cf. "Dès lors que le latin admet le barbarisme, il cesse d'être barbare. Il n'y a pas de barbarismes dans les langues barbares qui sont uniformément vouées à l'alterité. On peut en revanche distinguer un latin pur des formes corrompues, où l'alterité s'est insinuée, mais d'où l'on peut et l'on doit l'extirper'. 
O que se delineia, portanto, é a representação, no discurso metalinguístico antigo, de uma modalidade de língua latina própria dos latinos, em oposição a outra modalidade, eivada de elementos estrangeiros, bárbaros. Isso quer dizer que, nos primórdios, a "norma de linguagem" era antes e, sobretudo, uma "norma social", definidora da presença da linguagem do "outro" na fala latina. Atestam isso, entre outras passagens, os adjetivos que passam a qualificar o 'bom latim', recomendado por Cícero, por exemplo, em seu Brutus, ao qualificar a linguagem das personalidades lá representadas, personalidades, em suma, antes de mais nada, exemplos de bons romanos: Graco: perbene Latine loqui (108); M. Aurélio Scauro: Latine eleganter loqui (135); Crasso: Latine loquendi accurata et sine molestia (143), etc..

Além disso, também Diomedes, gramático do século IV, oriundo da parte oriental do Império ${ }^{12}$, apresenta a oposição entre uma variedade "bárbara" e outra "erudita" da língua latina; oposição que, novamente, identifica os romanos entre os não romanos, mas que, por esse viés, contribui para a estipulação de uma "norma" linguística, de expressão central na codificação dos fenômenos de linguagem desenvolvidos no âmbito das artes grammaticae:

Latinitas é o cuidado com o falar de forma incorrupta, de acordo com a língua romana. Consta, além disso, conforme afirma Varrão, destas quatro propriedades: natureza, analogia, uso e autoridade. A natureza das palavras e dos nomes é imutável; ela nos transmitiu nada a mais ou a menos do que o recebido. De fato, se alguém disser scrimbo em vez de scribo, não por força da analogia, mas da própria natureza será convencido do que se trata. A analogia da linguagem produzida de acordo com a natureza é, segundo os especialistas, não outra coisa que a distinção entre uma língua bárbara e uma erudita, como a prata se separa do chumbo. ${ }^{13}$

(Diomedes, Diom., GL, I, 439, 10)

${ }^{12}$ A julgar pelo seu nome, de origem grega, e a dedicatória a uma personalidade do mundo helenofônico, Atanásio (LAW, 1987, p. 20; KASTER, 1988, p. 394).

${ }^{13} \mathrm{Cf}$. Latinitas est incorrupte loquendi obseruatio secundum Romanam linguam. constat autem, ut adserit Varro, his quattuor, natura analogia consuetudine auctoritate. Natura uerborum nominumque inmutabilis est nec quicquam aut minus aut plus tradidit nobis quam quod accepit. nam siquis dicat scrimbo pro eo quod est scribo, non analogiae wirtute sed naturae ipsius 
O que avulta da passagem acima é, sem dúvida, a vinculação explícita entre o significado de Latinitas e a "romanidade" da língua. Mais que uma variedade de prestígio, parece estar em jogo uma questão de identidade cultural: a corrupção linguística denota uma equivalente impureza na origem de seu falante. Além disso, é digno de nota o fato de que a Latinitas se sustenta sobre quatro critérios: natureza (natura), analogia (analogia), uso (consuetudo) e autoridade (auctoritas). Conforme vimos no item anterior, também Quintiliano considerara, entre os elementos da linguagem, o uso e a autoridade como critérios para a elaboração de uma norma, o que revela, sem dúvida, certa continuidade entre os saberes da ars grammatica e da ars rhetorica, reflexo do fato de que ambas eram etapas escolares para a formação do romano culto.

A mesma representação de Latinitas como a norma de caráter social/ étnico e linguístico pode também ser observada nas definições dos desvios de linguagem catalogados pelos gramáticos como "barbarismos". Para ilustrar, citamos e comentamos como esse conceito aparece em Donato e em Diomedes, gramáticos latinos do século IV:

O barbarismo é uma parte da oração que é viciosa na fala comum; nos poemas é um metaplasmo, e, do mesmo modo, barbarismo, em nossa língua, diz-se barbarolexis no estrangeiro, como se alguém disser mastruga ${ }^{14}$, cateia $^{15}$, magalia ${ }^{16}$. O barbarismo se faz de dois modos, falado e escrito, que se subdividem em quatro espécies: adição, supressão, alteração de letra, sílaba, tempo, tom ou aspiração ${ }^{17}$.

(Donato, Ars, GL IV, 367)

constitutione conuincitur. analogia sermonis a natura proditi ordinatio est secundum technicos neque aliter barbaram linguam ab erudita quam argentum a plumbo dissociat.

${ }^{14}$ Vestido de pele, palavra de origem sarda.

${ }^{15}$ Espécie de dardo, arma utilizada pelos gauleses, palavra de origem provavelmente gaulesa ou germânica.

${ }^{16}$ Cabanas, choupanas, palavra fenícia.

${ }^{17}$ Barbarismus est una pars orationis uitiosa in communi sermone; in poemate metaplasmus, itemque in nostra loquella barbarismus, in peregrina barbarolexis dicitur, ut siquis dicat mastruga cateia magalia.

Barbarismus fit duobus modis, pronuntiatione et scripto. His bipertitis quattuor species subponuntur: adiectio, detractio, inmutatio, transmutatio litterae, syllabae, temporis, toni, adspirationis. 
Evidencia-se, no trecho citado da Ars maior de Donato, uma definição do fenômeno do barbarismo de forma dupla: por um lado, identifica-se a sua relação com as palavras estrangeiras, de origem bárbara: gaulesa, sarda, germânica, fenícia, etc., ali exemplificadas pelos itens lexicais mastruga (peça de vestuário sardo), cateia (espécie de armamento gaulês); magalia (provavelmente palavra de origem fenícia, que fazia referência a determinado tipo de cabanas); e, por outro, pelas características que uma fala estrangeira poderia imprimir à realização fônica das palavras latinas, alterando-lhe a sequência de fonemas seja pela adição (adiectio), supressão (detractio), ou alteração (inmutatio) de sons (litterae), sílabas (syllabae), tempos (tempora), tons (toni) ou aspirações (adspirationes).

Com isso, não se deixa de associar, novamente, o barbarismo a uma identidade estrangeira, mas se vai além: através de uma observação que resulta de uma análise dos sons da língua, identificam-se, por assim dizer, aquelas categorias próprias do sistema fonológico latino clássico, em contraste com a fala dos não romanos: os sons, as sílabas, as aspirações e os tempos. Em suma, pelo viés da Latinitas, assistimos, portanto, no âmbito da ars grammatica romana, a uma preocupação mais específica que levaria à análise da língua latina, a princípio para reconhecer-lhe os traços próprios da fala dos bárbaros, mas que, progressivamente, vai se tornando um estudo válido por si mesmo.

Diomedes apresenta sua definição de barbarismo, novamente identificando-o à fala estrangeira, mas também já apreciando as consequências dessa fala para os sons em geral da língua. A relação barbarismo/fala bárbara pode ser identificada na passagem:

Barbarismo é uma palavra escrita ou falada de forma viciosa contra a lei da fala romana; barbarismo é uma parte da oração enunciada ou escrita corrompida e, portanto, não-latina. Barbarismo é barbaros lexis, isto é, palavra bárbara. ${ }^{18}$

(Diomedes, Diom., GL I, 451)

${ }^{18}$ Cf. Barbarismus est contra Romani sermonis legem aut scripta aut pronuntiata uitiose dictio, barbarismus est enuntiatione uel scripto una pars orationis corrupta ac per hoc non Latina. Barbarismus est barbaros lexis, id est barbara dictio. 
Assim como em Donato, Diomedes identifica a origem etimológica do conceito que utiliza, através da citação, transliterada, do sintagma grego 'barbaros lexis' (i.e. 'palavra bárbara, estrangeira). Talvez aqui perguntássemos por que o grego, cuja presença, de fato, também configura um 'estrangeirismo' na língua latina, não é pelos gramáticos considerado um barbarismo, sendo talvez a única língua cuja presença em latim não poderia ser qualificada como bárbara. Diga-se de passagem que Donato, citado acima, empregou um adjetivo "neutro" ao se referir à presença do grego em latim: peregrinus (estrangeiro, oriundo de região estrangeira) e não barbarus (bárbaro, estrangeiro, inculto, rude).

\section{Conclusão}

A análise dos textos metalinguísticos da tradição greco-romana, especialmente dos tratados de retórica e gramática latinos, leva-nos a reconhecer certa consciência do caráter histórico da linguagem, evidenciado pela constatação em Quintiliano, Donato e Diomedes de que a linguagem instanciava diferentes usos: um uso característico da fala dos cidadãos cultos e letrados e, portanto, apropriado à elaboração de discursos oratórios no âmbito da retórica romana; um uso contemporâneo da linguagem, em oposição a expressões antigas da língua; um uso próprio dos cidadãos romanos, em oposição aos usos "estrangeiros" ou "bárbaros". O reconhecimento de usos da linguagem acarretava, portanto, a observação do fato empírico de que as línguas não eram uniformes, mas variáveis.

Uma das variantes da língua latina de prestígio social era, ao mesmo tempo, identitária dos romanos e tinha como propriedade a adequação a determinada norma de caráter social e linguístico, a Latinitas. Desvios a essa "norma" engendravam construções variantes da língua, que poderiam representar "vícios", se empregadas contrariamente à tradição, ou "virtudes", se atestadas no uso dos autores canônicos, o que revelava, sem dúvida, uma relatividade da noção de norma, que era contextualmente dependente. Além disso, a importância que os textos da tradição conferiam à estipulação da norma e à análise dos gramáticos exemplificava, igualmente, a dependência da ars grammatica aos saberes oriundos dos textos poéticos e retóricos, de acordo com a função sobretudo escolar desse gênero textual. 


\section{Referências}

BAGNO, M. O preconceito lingüistico. O que é, como se faz. São Paulo: Loyola, 2001.

BARATIN, M. Les difficultés de l'analyse syntaxique. In: AUROUX, S. (Ed.). Histoire des idées linguistiques. t. 2. Le développement de la grammaire occidentale. Liège: Mardaga, 1993.

BERRY, D. H. Oratory. In: HARRISON, S. (Org.) A companion to Latin literature. Oxford: Blackwell, 2005. p. 257-269.

CANTÓ, J. Los 'grammatici': críticos literarios, eruditos y comentaristas. In: CODOÑER, Carmen. Historia de la Literatura Latina. Catedra, 1997. p. $741-753$.

COSERIU, E. Sincronia, diacronia e história. Tradução de C. A. Fonseca e M. Ferreira. Rio de Janeiro: Presença, 1979.

DESBORDES, F.; BARATIN, M. L'analyse linguistique dans l'Antiquité Classique. Paris: Klincksieck, 1981.

DESBORDES, F. Idées grecques et romaines sur le langage - travaux d'histoire et d'épistémologie. Lion: ENS, 2007.

DÍAZ Y DÍAZ, M. C. 'Latinitas' - sobre la evolución de su concepto. Emerita, n. 19, p. 34-40, 1951.

DIOMEDES. Diomedis ars. In: KEIL, H. (Ed.). Grammatici Latini, I, 299529. Leipzig: Teubner, 1855-1880 [repub. Hildesheim: Olms, 1981].

DONATO, E. Donati ars maior. In: KEIL, H. (Ed.). Grammatici Latini, IV, 367-402. Leipzig: Teubner, 1855-1880 [repub. Hildesheim: Olms, 1981].

FORTES, F. da S. Sintaxe greco-romana: Prisciano de Cesareia e Apolônio Díscolo na história do pensamento gramatical antigo. 2012. Tese (Doutorado em Linguística - Estudos Clássicos) - Universidade Estadual de Campinas, Campinas. 2012. 
HORÁCIO, Q. F. Ars Poetica. Tradução inglesa de H. R. Fairclough. The Loeb Classical Library. Londres/Cambridge, Mass.: Harvard University Press, 1991.

LAUSBERG, H. Elementos de retórica literária. Tradução, prefácio e aditamentos de R. M. R. Fernandes. Lisboa: Calouste Gulbenkian, 1973.

MARROU, H.-I. História da educação na Antiguidade. Tradução de M. L. Casanova. 4. ed. São Paulo: MEC, 1975.

MATTOS E SILVA, R. V. Caminhos da Linguística Histórica. Ouvir o inaudível. São Paulo: Parábola, 2008.

PEREIRA, M. A. O discurso gramatical antigo, seu reflexo em Quintiliano e sua repercussão: algumas questões. 2003. Tese (Doutorado em Letras) Universidade de São Paulo, São Paulo. 2002.

PEREIRA, M. A. Quintiliano Gramático: o papel do mestre de gramática na Institutio oratoria. 2. ed. São Paulo: Humanitas, 2006.

[PS.-CÍCERO]. Retórica a Herênio. Tradução de Ana Paula C. Faria e Adriana Seabra. São Paulo: Hedra, 2005.

[PS.-CÍCERO]. Rhetorica ad Herennium. Tradução inglesa de H. Caplan. Cambridge, Mass.: Harvard University Press, 1999.

QUINTILIANO. Marcus Fabius. Fabii Quintiliani Institutionis oratoriae libri duodecim. Edição de M. Winterbottom. Oxford: Clarendon, 1989. $2 \mathrm{v}$

SAUSSURE, F. de. Curso de Lingüistica Geral. Tradução de Isaac Salum. 5. ed. São Paulo: Cultrix, 1973.

WEINREICH, U.; LABOV, W.; HERZOG, M. Fundamentos empiricos para uma teoria da mudança lingüística. Tradução de Marcos Bagno. São Paulo: Parábola, 2006 [1968]. 